\title{
Events in the Economy
}

\author{
Martin Vlček \\ eFunctionality, Non-Profit Research Group, Pardubice, Czech Republic \\ Email: martin.vlcek@efunctionality.eu
}

How to cite this paper: Vlček, M. (2017) Events in the Economy. Open Access Library Journal, 4: e3631. https://doi.org/10.4236/oalib.1103631

Received: April 24, 2017

Accepted: May 22, 2017

Published: May 25, 2017

Copyright $\odot 2017$ by author and Open Access Library Inc.

This work is licensed under the Creative Commons Attribution International License (CC BY 4.0).

http://creativecommons.org/licenses/by/4.0/

\begin{abstract}
At the time of modeling the Czech macro-economy in the Czech Ministry of finance a non-econometric model was used. Thanks to this it was determined that among some parts of the economic system there exists a communication based upon repeating features-events. Afterward using these events the model was developed with a result to become an important instrument of the department of macroeconomic forecasts in the ministry [1]. At the same time a generalization of control mechanisms was made. The control of elements in the object similarly as their mutual communication stems upon complexes of information. These complexes-events are for every specialization of elements typical. On one side it goes about a simplifying description of the activity of an element used for needs of the control and on the other side it goes about a sufficiently complex description been not only exhaustive but also enough resistant against the noise in the system. The event is formed from a certain alphabet of activities and has a standard structure. There differ thus only letters of the alphabet been part of the event. Every element has for its event that characterizes it in the system of its typical time, too. This time is linked to the time of the system as whole and through this systemic time every element is synchronized. Then a formation and spreading of events over the structure of the system is a manifestation of this synchronization. As a result of this a new level of aggregation of information arises-an aggregation of events, a theorem. The control system makes on its basis an organization of the object in a manner to fulfill its main task-the maximization of the existence of the object.
\end{abstract}

\section{Subject Areas}

Economic System, Economics

\section{Keywords}

Economy, Events, Control, Information, Holism

\section{Introduction}

The general principle of organization of an object is presented and discussed on 
a basis of a work of a model. Every mentioned property is more or less evaluated through calculations of the model. Nevertheless it does not mean that it is possible to exclude possible mistakes or inaccuracies, and this proving process is only relative and limited. But it is a formal process.

Task of the model was to discover a mechanism of communication and of control in the system. That is why it functioned as a certain translator which of course primarily meant to find out words or events to be translated. Thus at the beginning there was only a hypothesis about their existence.

Firstly the model in an immense amount of relations among elements of the object identifies repeated situations. They will be a real basis for events that are their simplification and denomination. Principle of works of the model is that it makes step by step simplification of a real, e.g. economic situation into a symbolism of events and monitors if it could be an event. If an event is well constructed, it is understood. It means that it provokes in the system and thus in the model, too, some impacts and that these impacts correspond to the real mechanism of communication and of control.

Every new property of an event is in the course of its verification monitored on the overall description of the system using different criteria. The main criterion in economical systems is a correctness of estimation of the GDP. If by its addition to the system an amendment of criteria happens, it is consider being true. The level of amendment is the level of the truth and the given system in a given state of knowledge is a relative frame for this truth.

As a result of generalization of the work of the model there is the notion of events in the economy. It expresses some not very frequently accepted relations between an informative notion of the event as a unit of communication and the real economy. But it is a also result of understanding the economy as a holistic object that means as an object with its own interests and problems aimed a maximization of its existence.

The main goal of this work is to describe the principle of functioning of the communication among parts of the economy from a holistic point of view. There is strictly proceeded on a basis of results of the structural model of events.

\section{Element and Events}

Element is a basic constituent of the object. It is a unit on what the system of control of the object operates. The final goal of this control is to reach an optimal distribution of interest of elements on their continuance in the object. This interest is monitored e.g. on dynamic of their migration over the border of the object. A broader notion than the migration is a general satisfaction of an element in the object.

There exists a structure of relations with other elements around an element. This structure brings influences from other parts of the object into the element and subsequently an influence of the element upon consequential elements. Apart from a transfer of economic activity there is also a transfer of information. And it is made in a form of events. 
An element (E) is a place of birth of an event communicating to its environment a fact that its typical activity was just realized. And in general, it does it in a form of a simulation and of a simplification of the given activity.

\section{Origin of an Activity of the Element}

An observer outside the system without any knowledge of the inner language has to use some apparatus of translation. In the case of submitted work this was the structural model of events. It is informed about a universal form of events in holistic systems and its work consists in an application of this knowledge on a concrete system-e.g. economic. It has to follow its activities through a slow work, step by step, and find out analogies of the holistic speech there.

An event describes the activity of $\mathrm{E}$ (the element) in the whole complex. Thus it goes about a summary of descriptions of inputs and of activities of $E$ itself what define this event as a whole. Only a repeating and summarizing occurrence of all these conditioning factors is an indicator of the fact that a given typical activity of E happened.

A real instrument through which the event spreads over the system can be different. It can be a human speech what spreads between appropriate elements in given specialized areas information about an occurrence of a given activity. But it can be a communication in a qualitatively new level.

The model identifies a real basis for a rise of an event. The fineness of its spreading it is already not able to identify, it is able to follow only its consequences.

Thus a description of a typical activity with what the model works is not from a communicative, informative level but it is its economic, real substance, fundament. It holds that it is defined by a set of typical activities not only of E, but also of cooperating elements (SE) and that this set is repeating.

\section{Structure of the Event}

Sometimes at the submitted paper an economic presumption of an event is named as an event itself, it means a sum of typical activities around E. And at the same time its informative projection, an instrument of control what spreads over the system and allows this control.

\subsection{First Level of the Event}

An event is composed from some levels. There is a similar logic as is used e.g. in the human speech. An event is a word having its universally understandable meaning. This word is placed among other words and forms a phrase, what means a unit of the message. In the case of economic events a phrase is formed in a manner that every event has its time what situates it among other events in a structure and all this is as a whole evaluated.

First complexes are, analogically as in the speech vocals from sounds, formed in the first level from elementary activities. In the economic case it goes about a simple reflection of economical activity and of its spreading. But because of the 
huge amount of data this reflection is possible to be recorded only through a model. Nevertheless it holds only for a human observer, the economic system understands this speech without a "translator".

The model follows activities of elements and searches those among them having an impact over others, surrounding E. Only those activities what in some manner manifest themselves in activities of the environment can be parts of an event. And for new this is the same as in the speech. Only a sound having an impact, a meaning over other peoples can be a part e.g. of a word. Only this one can be a vocal.

After on the model has to solve a problem how to monitor surrounding elements in what the supposed input of a potential vocal can happen. For this reason the model identifies a group of elements (SK) around the investigated $\mathrm{E}$ in what are elements having their mutual-and with E-feedbacks as maximally as possible closed in. By other words the group SK is chosen by the model in a manner to include elements having very narrow interactions. That is why an understanding of an event connected with $\mathrm{E}$ will be manifested there but also events of other members will be probably identified in remaining members, included the $\mathrm{E}$. Thus it is a group where is the highest chance to monitor the event of $\mathrm{E}$ on remaining events and throughout these events.

On the first level the model composes relations in a manner that two describing formations arise. The first one describes a character of entering relations into E from the group SK, the second one inversely from E into the group SK. The model has to its disposal a known, verified set of definitions of events, what was verified during a study of holistic systems. Every such a definition is composed from a description of course of activities and the model investigates whether given course corresponds to the given event. E.g. let for a given event the following equations prescribe a typical course of activities. The first one, what describes the dynamic from the group SK toward the E, tells that a depression is expected-with an intensity of 1 . The second one tells that from the $\mathrm{E}$ toward the group SK there is an increase of activity-with an intensity of 2.

1) $\mathrm{prac}=$ prac $-1^{\star}$ udalostiRgIPlus $(\mathrm{pi}, \mathrm{k}, \mathrm{po}+\mathrm{pk})$

2) $\mathrm{prac}=\mathrm{prac}+2 *$ udalostiRgIPlus $(\mathrm{rg}, \mathrm{pi}, \mathrm{po}+\mathrm{pk})$

The quantity udalostiRgIPlus ( $p i, k, p o+p k$ ) represents an increment of activity of $\mathrm{E}$ (pi) coming from the group (k) at time $(p o+p k)$. By other words it goes about an increment to the total activity of $\mathrm{E}$ being attributed on the basis of calculus of the model to an element $k$ (from the group).

Every equation has its own quantity udalostiRgIPlus with a sign telling if the result of the relation is an increment or a decrement of the activity. That is why in the quantity prac there are subsequently added partial characteristics of the event. If they are fulfilled with a positive sign, if not with a negative one. Thus the resulting value of the quantity prac tells what is the probability that the given event being universally defined really occurred in the activity of $E$ and of its environment.

Thus the mentioned part of an event-the vocal-described by equations 1 and 2 
could be symbolically named as MP. This says that in one direction there was a decrement in the relation- $\mathrm{M}$ as a minus and in the second one an increment one- $\mathrm{P}$ as a plus.

Every event of the first level-the vocal, thus describes spreading of the activity among $\mathrm{E}$ and its environment in the group SK. By this way a certain alphabet of spreading arises and its elements are e.g.:

\begin{tabular}{|c|c|c|c|}
\hline MP & minus, plus & minus $E$, plus SK & $\begin{array}{l}\text { activity goes from } \mathrm{E} \text { into } \mathrm{SK} \text {, } \\
\text { the environment }\end{array}$ \\
\hline PM & plus, minus & plus $E$, minus $S K$ & activity goes from SK into $E$ \\
\hline $\mathrm{MM}$ & minus, minus & minus $\mathrm{E}$, minus SK & $\begin{array}{l}\text { decrement of the activities in both } \\
\text { parts and its spreading only at other } \\
\text { time }\end{array}$ \\
\hline PP & plus, plus & plus $E$, plus $S K$ & $\begin{array}{l}\text { increment of the activities in both } \\
\text { parts - the source of it is at other time }\end{array}$ \\
\hline \multirow[t]{3}{*}{ MaP } & minus of absolute value, plus & \multirow{3}{*}{\multicolumn{2}{|c|}{$\begin{array}{l}\text { Ma mean } \\
\text { to the abs } \\
\text { negative }\end{array}$}} \\
\hline & & & \\
\hline & & & \\
\hline XPP & max of absolute value, plus & \multicolumn{2}{|c|}{$\begin{array}{l}\mathrm{XP} \text { means that a maximal value from all absolute values of } \\
\text { relations is taken in as a positive one }\end{array}$} \\
\hline $\mathrm{Pu}$ & no regularity & \multicolumn{2}{|c|}{$\begin{array}{l}\text { there is nothing important in the dynamic of transfer of } \\
\text { the activity, there is only an important value of its own } \\
\text { activity of E. }\end{array}$} \\
\hline
\end{tabular}

\subsection{Second Level of a Description of an Event}

The first level of events named as their alphabet describes distribution of the activity at individual time spots. E.g. MM tells that at the monitored time changes induced by entering relations into $\mathrm{E}$, similarly as outputting into SK, gain negative values. That is why it goes about a fall of activity.

Now the second level describes how this distribution develops at time. That firstly there where a release of relations what being though at the following time followed by an opposite-a growth of activity in both parts.

Then the whole event is usually a sequence of three elements from the alphabet-e.g. MM, SvSv and Pu. Another frequent event is MaP, MaP and MaP.

A special type of description represents services. E.g. if MM precedes the XPP in the description of the event, it goes about one type of services-the input of them. If in opposite as first is the XPP and only at the following time the MM, it goes about the output of services from the system.

\subsection{Describing Situation-Retsubsit}

Every event is a specific word-a sequence of specific letters. The model uses for the identification of events also another-nonverbal-instrument. That is because it discovered during its work with events that there exist also another manifestations of the behavior of an element. These manifestations are common to all 
events and that is why it is possible to use them as a sustaining instrument in the identification. By other words it goes about a nonverbal trail same for all events.

\subsubsection{Satisfaction and Tension}

Nonverbal quantity are two-the satisfaction and the tension. Satisfaction is given by a level of evenness of relations of the element. The notion of the satisfaction is only a euphemism and it goes about a parable with biological systems. The tension shows a maximal difference among values of interactions of the element. The tension itself is nothing "wrong". It forms the information what the element uses in the process of its satisfaction augmentation.

The model follows all on a quantity named udalosti, what content represents these nonverbal quantities. It is defined through the last parameter. 1 is satisfaction, 5 tension.

The whole process is at times $+1,0,-1$. From historical reasons the time goes here inversely-from +1 to -1 . Firstly at time +1 there is an increase of the tension and simultaneously a decrease of the satisfaction. This is described through Equations (4) and (6). Subsequently at time 0 the tension returns to its initial values and at time -1 the same makes the satisfaction, too. Similarly as in other parts of an event the identification is as probable as positive are values reaches by the quantity.

3) $\operatorname{prac}=\operatorname{prac}+$ udalosti $(1$, po $-1+\mathrm{pj}, 1)$

4) $\operatorname{prac}=\operatorname{prac}-$ udalosti $(1$, po $+1+$ pj, 1$)$

5) $\operatorname{prac}=\operatorname{prac}+$ udalosti $(1, \mathrm{po}+\mathrm{pj}, 5)$

6) $\operatorname{prac}=\operatorname{prac}-$ udalosti $(1$, po $+1+$ pj, 5)

Analogically as mentioned quantities monitor values of the element E-see the first parameter 1 , following quantities monitor the development in other time series $r g$ for $\mathrm{SK}$.

7) $\operatorname{prac}=$ prac + udalosti $(\mathrm{rg}$, po $-1+\mathrm{pj}, 1)$

8) prac $=$ prac - udalosti $(\mathrm{rg}, \mathrm{po}+1+\mathrm{pj}, 1)$

9) $\operatorname{prac}=\operatorname{prac}+$ udalosti $(\mathrm{rg}, \mathrm{po}+\mathrm{pj}, 5)$

10) $\operatorname{prac}=$ prac - udalosti $(\mathrm{rg}, \mathrm{po}+1+\mathrm{pj}, 5)$

\subsubsection{Dynamics}

Relations among just mentioned nonverbal quantities describe following equations. E.g. the Equation (11) tells that as the satisfaction diminishes at the beginning of the event as it augments at the second part.

11) $\operatorname{prac}=\operatorname{prac}-\operatorname{Abs}(\operatorname{udalosti}(1$, po + pj, 1$)+\operatorname{udalosti}(1$, po $-1+$ pj, 1$))$

12) $\operatorname{prac}=\operatorname{prac}-\operatorname{Abs}(\operatorname{udalosti}(1, \mathrm{po}+\mathrm{pj}, 5)+\operatorname{udalosti}(1, \operatorname{po}+1+\mathrm{pj}, 5))$

13) $\operatorname{prac}=\operatorname{prac}-\operatorname{Abs}($ udalosti $(r g, p o+p j, 1)+$ udalosti $(r g, p o-1+p j, 1))$

14) $\operatorname{prac}=\operatorname{prac}-\operatorname{Abs}($ udalosti $(\mathrm{rg}, \mathrm{po}+\mathrm{pj}, 5)+$ udalosti $(\mathrm{rg}, \mathrm{po}+1+\mathrm{pj}, 5))$

\subsubsection{Relations}

In contrast with the quantity udalosti describing development of the satisfaction and the tension, the quantity udalostiRgIPlus describes a development of general relations among monitored elements. The first two parameters identify the be- 
ginning and the end of the relations. Thus if there is $p i, p i$, it goes about a relation inside the same element $p i$-about the memory. Equations (15) till (18) tell that starting with time +2 and also at time +1 there is firstly a diminishing of an intensity of the relation and only subsequently at times 0 and -1 its strengthening. Similar equations hold also for parameters $\mathrm{rg}$, rg, what means for accompanying elements.

Because it goes about relations into pi, it means about a memory, firstly at time +2 and +1 happens diminishing of the role of the memory and inversely at following steps its increasing. It is possible to interpret it also in a manner that in a part being connected with usage of the tension mainly information about the environment are used. In contrast with it in part connected with a satisfaction solving a bigger role plays the experience.

15) $\mathrm{prac}=\operatorname{prac}+1^{\star}$ udalostiRgIPlus (pi, pi, po -1$)$

16) $\mathrm{prac}=\operatorname{prac}+1^{\star}$ udalostiRgIPlus $(\mathrm{pi}, \mathrm{pi}, \mathrm{po}+0)$

17) $\operatorname{prac}=\operatorname{prac}-1 *$ udalostiRgIPlus $(\mathrm{pi}, \mathrm{pi}, \mathrm{po}+1)$

18) $\mathrm{prac}=\operatorname{prac}-1{ }^{\star}$ udalostiRgIPlus $(\mathrm{pi}, \mathrm{pi}, \mathrm{po}+2)$

\subsection{Structure of Relations}

A phrase is composed from words and it is a statement about the state of the object. And it is reached through the fact that events-words-form another structure, a phrase. In this structure every event has its place and time.

A typical phrase what is a statement intended for the environment of the object-not only of the element-was observed in American Stock Markets [2] [3] and [4] as an activity of an area of the object connected with the activity of the border of the object and controlled from the highest level from the area of the global tension. This activity - a speech-was intended for the environment of the system and this environment was firstly individual consumers and secondly firms out of the American Market.

\section{Conclusions}

Through the structural model of events a structure of functioning of economical systems was discovered and its extrapolation into other systems was proposed too. This holistic structure stems upon elements and upon the instrument of their communication, which is the event.

Its holisticity consists in the control of the object as whole and in the fulfilling of holistic goals of the object.

Events are a basic stone of the holistic approach. Only through this approach is it possible to put up over elements the system of the control working with elements as informative units. These events are a universal unit that was proven not only in macroeconomics but also in the economics of Stock Markets. This speech is ever the same. And there is a preposition that it is same or analogical also in other, non-economic systems. This is the speech of holistic systems.

The main contribution of this work is an illustration of implementation of a non-econometric model. From the point of view of generalization it goes about 
an illustration of a holistic approach in practices. And at the end the holistic point of view is a benefit itself because until now it is minimally widen among economical society. Its contribution can be manifested in GDP holistic studies - see [5] and in associated economic area-see [6] and [7].

In the limitation of this work it is possible to see it in a relatively small application of the structure of the banking sector into calculations. Last researches in the area of Stock Markets show that this structure is quite decisive in the functioning of a holistic system.

\section{References}

[1] Vlcek, M. (2010) Movers of the Economy-Model of Interactions. Developments in Economic Theory and Policy Proceedings, Bilbao.

[2] Vlcek, M. (2014) New Object Discovered through the Stock Market. International Conference on Economics and Finance Research Proceedings, Seoul.

[3] Vlcek, M. (2015) Relations among American Firms Allow the Rise of a New Object. American Journal of Economics, 5, 423-427.

[4] Vlcek, M. (2016) Holistic Economics and Stock Markets. Scholars' Press.

[5] Vlcek, M. (2016) Would you Like a GDP with Your Coffee? Journal of Economics and Public Finance, 2, 22-26.

[6] Vlcek, M. (2015) Firm without Subordinations. American Journal of Economics, 5, 333-336.

[7] Vlcek, M. (2015) Society and Its Way to the Happiness. American Journal of Economics, 5, 405-408.

Submit or recommend next manuscript to OALib Journal and we will provide best service for you:

- Publication frequency: Monthly

- 9 subject areas of science, technology and medicine

- Fair and rigorous peer-review system

- Fast publication process

- Article promotion in various social networking sites (LinkedIn, Facebook, Twitter, etc.)

- Maximum dissemination of your research work

Submit Your Paper Online: Click Here to Submit

Or Contact service@oalib.com 